\title{
Behavioral and patho-physiological response as possible signs of pain in dairy cows during Escherichia coli mastitis: A pilot study
}

\author{
Alice de Boyer des Roches, ${ }^{* 1}$ Marion Faure, ${ }^{*}$ Alexandra Lussert, $†$ Vincent Herry, $†$ Pascal Rainard,‡ \\ Denys Durand,* and Gilles Foucras $†$ \\ *Université Clermont Auvergne, Institut National de la Recherche Agronomique (INRA), VetAgro Sup, UMR Herbivores, \\ F-63122 Saint-Genès-Champanelle, France \\ †Université de Toulouse, Ecole Nationale Vétérinaire de Toulouse (ENVT), INRA, Interactions Hôtes-Agents Pathogènes (IHAP), \\ F-31076 Toulouse, France \\ ‡Infectiologie et Santé Publique (ISP), INRA, Université de Tours, UMR1282, F-37380 Nouzilly, France
}

\begin{abstract}
Bovine mastitis is one of the most common diseases in the dairy industry and it is a major welfare problem. Pain during mastitis is generally assessed through behavior but a combination of indicators would increase the chances of detecting pain and assessing its intensity. The aim of this study was to assess behavioral and patho-physiological responses as possible signs of pain experienced by cows after experimental intramammary challenge (mastitis) with Escherichia coli. Six HolsteinFriesian cows received an inoculation of E. coli $\mathrm{P} 4$ in one healthy quarter. Evolution of the disease was assessed using bacteriological growth and somatic cell counts (SCC). Cows' response to the challenge was monitored by direct behavioral and clinical observations, data loggers, rumen temperature sensors, and indicators of inflammation, stress, and oxidative status. From all data recorded, the variables that contributed most to the discrimination of mastitis phases were obtained by factorial discriminant analysis. Baseline levels of all indicators corresponded to values before challenge. Specifically, we weighted data relating to lying behavior by the observations at the same hour of the day before challenge to eliminate the circadian rhythm effect. We identified 3 phases that were discriminated by factorial discriminant analysis with good performance. Nine indicators varied according to the phase of the disease: cows' attitude toward their surroundings, tail position, clinical signs, ear position, variation of postural changes, concentrations of haptoglobin and serum amyloid A (SAA), cortisol blood levels, and rumen temperature (as a surrogate for body temperature). In phase 1 (4 to $8 \mathrm{~h}$ postinoculation), $E$. coli proliferated exponentially in milk but inflamma-
\end{abstract}

Received February 24, 2017.

Accepted May 31, 2017.

${ }^{1}$ Corresponding author: alice.deboyerdesroches@vetagro-sup.fr tion indicators remained at baseline levels. Cows were less attentive toward their surroundings (median score, 0.63 ), and postural changes (lying/standing) were less frequent ( 0.75 times from baseline). In phase 2 (12 to $24 \mathrm{~h}$ postinoculation), bacterial concentrations peaked around $12 \mathrm{~h}$ and then began to decrease concomitantly with a sharp SCC increase. Cows were less attentive toward their surroundings (score, 0.54), had high plasma cortisol $(31.3 \mathrm{ng} / \mathrm{mL})$ and SAA $(100.3 \mu \mathrm{g} / \mathrm{mL})$ concentrations, and rumen temperature was increased $\left(40.3^{\circ} \mathrm{C}\right)$. In phase 3 (32 to $80 \mathrm{~h}$ postinoculation), bacterial concentrations decreased concomitantly with high SCC levels. Cows had high levels of haptoglobin $(0.57 \mathrm{mg} / \mathrm{mL})$ and SAA $(269 \mu \mathrm{g} / \mathrm{mL})$ but showed no behavioral changes. Dairy cows displayed changes of behavioral, inflammatory, and stress parameters after E. coli mammary inoculation. Our results suggest that cows may have experienced discomfort in the preclinical phase (phase 1) and pain in the acute phase (phase 2) but neither discomfort nor pain in the remission phase (phase 3). Although larger controlled studies are needed to confirm our findings, this knowledge could be useful for early detection of $E$. coli mastitis and for decision-making regarding the initiation of pain-relief treatment during mastitis in dairy cows. This would improve animal welfare and potentially faster disease remission.

Key words: dairy cow, mastitis, pain, multiparametric analysis, Escherichia coli

\section{INTRODUCTION}

Mastitis is one of the major problems affecting the welfare of dairy cows (European Food Safety Authority, 2009; Leslie and Petersson-Wolfe, 2012). During mastitis, the concomitant inflammation of the udder, increased intramammary pressure, and increased external pressure (e.g., from an adjacent limb on a swollen udder) are believed to induce pain (Fitzpatrick et al., 2000; Leslie and Petersson-Wolfe, 2012). Recently, 
cattle practitioners in the United Kingdom scored pain associated with acute Escherichia coli mastitis at 7 on a value scale from 0 to 10 (Huxley and Whay, 2006). Unfortunately, the management of painful conditions in cattle is still infrequently considered in practice (Hudson et al., 2008), although treating the pain experienced by cows during clinical mastitis results in decreased edema, a lower SCC, and a reduced risk of culling (McDougall et al., 2009; Fitzpatrick et al., 2013). One reason for the inconsistencies of pain relief in cattle is the difficulty in assessing pain properly (Huxley and Whay, 2006; Flecknell, 2008).

Numerous methodologies have been used to assess or quantify the levels of pain experienced by farm animals (Prunier et al., 2013). Studies on pain mainly measure an animal's pain response to a noxious stimulus by recording the incidence of a clearly defined pattern of behaviors (e.g., abnormal standing or lying; Fogsgaard et al., 2012, 2015), changes in the levels of stress response [e.g., hypothalamus-pituitary-adrenal (HPA) axis such as cortisol release (Hopster et al., 1998) or autonomous nervous system such as heart-rate increase (Fitzpatrick et al., 2000)], or in levels of biochemical markers of oxidative stress (Salvemini et al., 2011; Sharma et al., 2016) and inflammation (e.g., haptoglobin and serum amyloid A, SAA; Eckersall et al., 2001). Unfortunately, it is not possible to allocate a "pain score" based on changes in only one of these indicators because most of them are not specific or sensitive enough. For instance, HPA axis and autonomous nervous system activity are related to stressful situations (Molony and Kent, 1997; Prunier et al., 2013). Changes in activity may result from pain (Theurer et al., 2012) but can also be early signs of sickness (Veissier et al., 1989). Previous studies on how cows feel pain during mastitis generally focused on 1 or 2 types of indicators (e.g., clinical and behavioral; Fogsgaard et al., 2012), but did not, to our knowledge, combine information of various types of indicators. Such a combination would increase the chance of detecting pain and assessing its intensity. Moreover, although the severity of mastitis is well described in the scientific literature (Schukken et al., 2011), knowledge is still lacking on the levels of pain experienced by cows according to the phase of the disease (e.g., preclinical, acute phase, and remission).

The aim of this study was to assess the behavioral and patho-physiological responses, as possible signs of pain experienced by cows during E. coli mastitis. We hypothesized that (1) the pain experienced by cows varies according to the timeline of E. coli mastitis, and (2) a multiparametric approach combining several indicators, already tested in experimental surgery conditions (Faure et al., 2017), would be efficient in discriminating pain levels during mastitis.

\section{MATERIALS AND METHODS}

This experiment was carried out with the approval of the Val de Loire Ethics Committee for Experiments on Animals (France; DGRI's agreement APAFIS\#8132015061109103810v2). Animal studies were compliant with all applicable provisions established by the European Directive 2010/63/EU.

\section{Animals, Housing, and Feeding}

The study was conducted at the INRA animal facility (PFIE, Nouzilly, France). Six Holstein-Friesian cows in their first parity were used. They were part of a larger study on the effect of local immunization on the response of dairy cows to $E$. coli mastitis (Herry et al., 2017). The 6 cows used in the current study were involved as a control group in the above-mentioned study that used 18 animals in total. Detailed information on the protocol can be found elsewhere (Herry et al., 2017). Here, only information relative to the 6 animals used in the current study is provided.

The 6 cows were housed in a loose housing, deepbedded barn (space allowance per cow, $20 \mathrm{~m}^{2}: 15 \mathrm{~m}^{2}$ of bedded area and $5 \mathrm{~m}^{2}$ of walking area) at INRA PFIE. They were fed once per day (at $1000 \mathrm{~h}$ ) a diet based on corn silage, hay, soybean meal, and concentrate, which met the dietary requirements for transition and early lactation. The mixed ration was regularly pushed back toward the cows during the day and refusals were always $>5 \%$. They were allowed water ad libitum. The cows were milked twice a day (at 0800 and $1600 \mathrm{~h}$ ) by experienced stockpersons in a milking parlor adjacent to the barn.

\section{Experimental Design}

The experiment was a longitudinal study, with the individual dairy cow being her own control, examining the effects of experimental E. coli infection. The E. coli strain P4 classified as O32:H37, ECOR Phylogenetic group A, and multilocus sequence type ST10 (Blum et al., 2012) was used for intramammary challenge as previously indicated.

Cows were challenged at 44 to 56 (average 49) DIM. Before challenge, all quarters were checked for the absence of IMI by performing bacteriological analysis and SCC measurement on foremilk stripping. Inoculated quarters were free of infection: the milk had SCC $<50,000$ cells $/ \mathrm{mL}$ and contained no viable bacteria. One quarter of each cow was challenged by infusion with $1 \mathrm{~mL}$ of the bacterial suspension $(1,000 \mathrm{cfu} / \mathrm{mL})$. Inoculation was performed at midnight on d 0 just after complete milking of the gland and $8 \mathrm{~h}$ before the next 
milking. Complete milkings subsequent to inoculation took place twice a day, and milk samples were collected at $8,16,32,40,56,64,80$, and $104 \mathrm{~h}$ postinoculation.

\section{Data Collection}

Milk samples, behavioral observations, and physiological measurements were performed at regular intervals from $42 \mathrm{~h}$ (behavior) or just before (time 0; milk, blood) E. coli inoculation up to $80 \mathrm{~h}$ postinoculation (Figure 1 ) by 2 experienced veterinarians.

\section{Milk Leukocytes, Bacterial Count, and Phase of Mastitis}

Bacteriological examinations were conducted over 80 $\mathrm{h}$ postinoculation (Figure 1). Somatic cell counts were determined from aseptically taken milk samples from the challenged quarters using a cell counter (Fossomatic model 90; Foss Food Technology, Hillerød, Denmark), and bacteriological analysis was performed by plating $50 \mu \mathrm{L}$ of 10 -fold dilutions of foremilk samples over sheep blood-esculin agar, incubating overnight at $37^{\circ} \mathrm{C}$, and enumerating E. coli colonies. Details of these procedures are described elsewhere (Herry et al., 2017).
Based on the kinetic variation in the milk bacterial population and SCC observed in the 6 cows, we divided the observational period into phases reflecting the evolution of the mastitis.

\section{Behavior Evaluation Scheme}

The behavior evaluation scheme was based on pain behaviors selected from the literature (Molony and Kent, 1997; Hudson et al., 2008; Siivonen et al., 2011; Mølgaard et al., 2012; Fogsgaard et al., 2012, 2015; Prunier et al., 2013; de Oliveira et al., 2014; Gleerup et al., 2015). The behaviors included in the evaluation scheme are described in Table 1. Based on the scientific literature, all behaviors were weighted and graduated in levels as some behaviors are considered more painspecific than others (Table 1; e.g., "absence of rumination" had a score of 1). Behavioral observations were conducted by scan sampling (Martin and Bateson, 2013) once at 13 time points (Figure 1) by one blind observer trained to observe animal behavior. Behavioral observations recording was made with an application (EvaDoul) developed by an INRA research team (INRA, Saint-Genes-Champanelle, France) installed on a digital tablet.

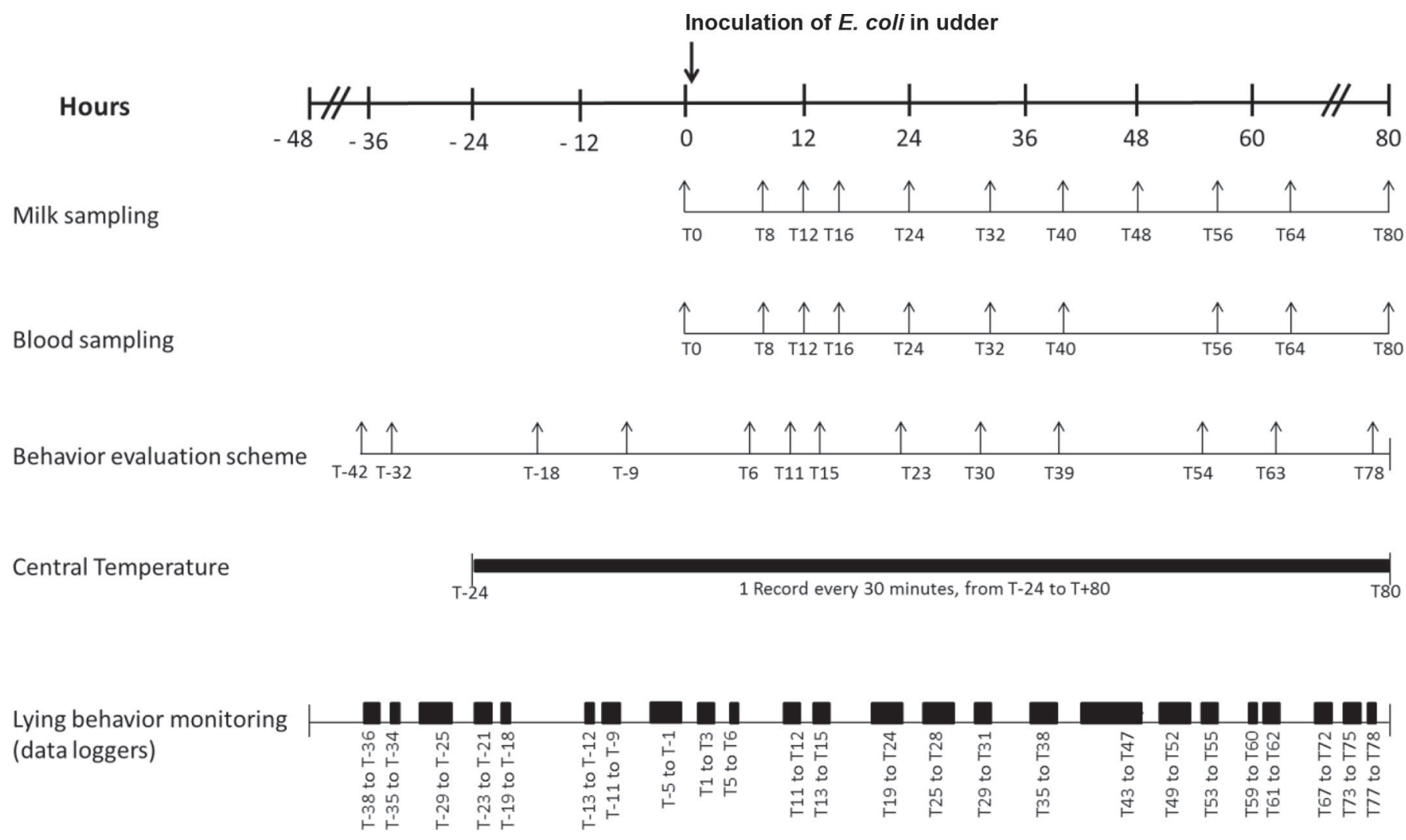

Figure 1. Experimental protocol for investigating the effects of inoculation of Escherichia coli in the udder of 6 Holstein-Friesian cows on milk indicators, physiological indicators, and behavioral indicators. Inoculation took place just after time (T) 0 hours. 
Table 1. Description of criteria evaluated in the behavior evaluation scheme

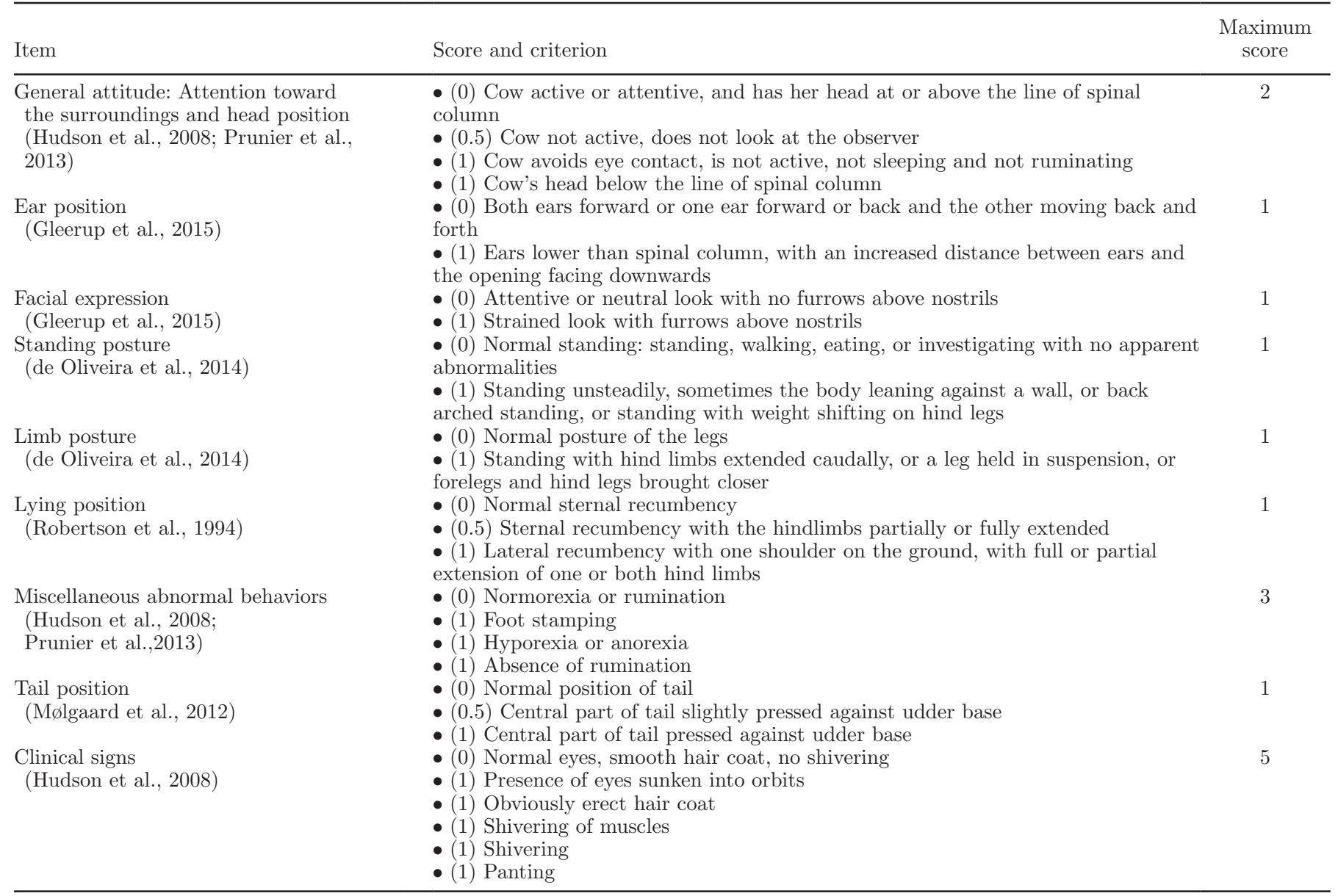

\section{Lying Behavior Monitoring}

Lying behavior was monitored with data loggers (Hobo Pendant G Data Logger, Onset Computer Corp., Pocasset, MA) attached to the medial side of the hind leg of each cow with Vet Wrap (3M Corp., St-Paul, $\mathrm{MN})$. Loggers were fixed in a position so that the $\mathrm{x}$-axis was parallel to the ground, the y-axis was perpendicular to the ground pointing upward, and the z-axis was parallel to the ground pointing away from the sagittal plane (Ito et al., 2009; Cyples et al., 2012). The loggers recorded the $g$-force on the $x$-, $y$-, and $z$-axes at 1 -min intervals from $48 \mathrm{~h}$ preinoculation until $80 \mathrm{~h}$ postinoculation, and the data were downloaded using Onset HOBOware software (Onset Computer Corp.), which converted the $g$-force readings into degrees of tilt. These data were exported into Excel (Microsoft Corp., Redmond, WA). Data were selected to keep lying/standing positions of the cows only when these activities were undisturbed by humans (Figure 1). This information was used to determine whether the cow was standing or lying. A macro was subsequently used to calculate the percentage of undisturbed time spent lying and the number of postural (standing/lying) changes per hour.

\section{Physiological Measurements}

Blood samples were collected by venipuncture from the jugular vein to determine physiological parameters at regular intervals from $0 \mathrm{~h}$ (i.e., just before $E$. coli inoculation), up to $80 \mathrm{~h}$ postinoculation (Figure 1). Blood samples were collected into evacuated tubes containing $\mathrm{Na}_{2}$-EDTA (2 tubes of $10 \mathrm{~mL}$ ) or lithium heparin ( 2 tubes of $10 \mathrm{~mL}$ ).

Haptoglobin and SAA plasma concentrations were determined by immunoprecipitation (Auboiron et al., 1990) and by ELISA kit (catalog no. TP 802, Tridelta Development Ltd., Maynooth, Co. Kildare, Ireland). Central body temperature was monitored every $30 \mathrm{~min}$ using a ruminal sensor (Thermobolus, Medria Elevage, Châteaubourg, France), validated to monitor dairy cows' health in commercial farms (Bareille et al., 2014).

Plasma cortisol concentration was determined by radioimmunoassay (Boissy and Bouissou, 1994). High- 
performance liquid chromatography was used to measure plasma concentrations of oxidized and reduced glutathione (GSH/GSSG; Martin and White, 1991).

\section{Statistical Analyses}

From the cows' response to E. coli mammary inoculation (i.e., counts of E. coli and SCC in milk), we identified 4 main phases of mastitis: phase 0 corresponded to times before inoculation ( -48 to $0 \mathrm{~h}$ ), phase 1 included 4 to $8 \mathrm{~h}$ postinoculation; phase 2,12 to $24 \mathrm{~h}$ postinoculation; and phase 3,32 to $80 \mathrm{~h}$ postinoculation.

For behavioral data recorded through the behavior evaluation scheme, we established behavioral categories ("item" in Table 1) that comprised several behavioral criteria (e.g., the item "miscellaneous abnormal behaviors" comprised normorexia and/or rumination, foot stamping, hyporexia or anorexia, and absence of rumination). For each cow in each phase and for each criterion, we multiplied its frequency of observation by its initial score, giving a weighted score. In each behavioral item, we first summed all the weighted scores for each cow at each phase and then divided this by the maximum reachable weighted score. The final composite score for each behavioral item was thus expressed on a $0-1$ value scale.

To eliminate the circadian rhythm effect on the cows' lying behavior (Veissier et al., 1989), we weighted the data relating to lying behavior (i.e., time spent lying and number of postural changes per hour) by the observations at the same hour on the day before challenge. We then calculated a ratio $=\left(\right.$ data from hour $H_{i}$ to hour $H_{j}$ observed postchallenge)/(data at hour $H_{i}$ to hour $H_{j}$ recorded $24 \mathrm{~h}$ prechallenge) for further analyses. This allowed us to assess the variation in postinoculation lying behavior indicators from baseline levels.

For all indicators (haptoglobin, SAA, cortisol, GSH/ GSSG, behavioral item score, lying behavior monitoring, rumen temperature), we calculated the mean value for each phase and each cow, and used it for further analyses.

We performed a factorial discriminant analysis to statistically discriminate the phases of mastitis disease. Discriminant analysis highlights the variables on which the $q$ groups differ and identifies at most $q-1$ linear combinations of variables that best discriminate the groups (Lebart et al., 1995). We ran the analysis using all the behavioral and physiological measures (inflammation, oxidative stress, HPA). To interpret the discriminant components (axes) of the factorial discriminant analysis, we focused on variables with a correlation of absolute value with the axis $>0.3$. We estimated the performances of the final predictive model on the current data set by running a leave-one-out cross-vali- dation, which calculates the probability for each animal to be accurately classified in the correct mastitis phase (Arlot and Celisse, 2010). This multiparametric analytical approach enabled us to calculate the probability of each cow belonging to each phase. The number of cows correctly classified after cross-validation enabled us to calculate the performance of the final model: accuracy $[$ (true positive + true negative)/(true negative + false negative + true positive + false positive)], sensitivity (percentage of cows correctly predicted to belong to a phase; true positive/true positive + false negative), and specificity (percentage of cows correctly predicted to not belong to a phase; true negative/true negative + false positive). Finally, we compared cows' responses between phases, taking into account the variables from the final model (see above). Because sample size was small $(\mathrm{n}=6$ cows $)$ and variables followed a non-normal distribution, nonparametric Friedman and post hoc Dunn tests were used. We fixed the significance threshold at $P=0.05$, and a trend was considered when 0.05 $<P<0.10$. Analyses were performed using R 3.3.2 (R Core Team, 2014) and XLSTAT 2015 (Microsoft Excel, https://www.xlstat.com/).

\section{RESULTS}

\section{Response to E. coli Inoculation and Determination of Mastitis Phases}

All cows included in the data set tested positively for E. coli bacteria upon inoculation. This model resulted in acute clinical mastitis, confirmed by the high variations in the number of $E$. coli and SCC in milk during the observation period (Figure 2). From the cows' response to E. coli mammary inoculation, we identified 4 main phases of mastitis: phase 0 corresponded to times before inoculation, phase 1 ( 4 to $8 \mathrm{~h}$ postinoculation), phase 2 (12 to $24 \mathrm{~h}$ postinoculation), and phase 3 (32 to $80 \mathrm{~h}$ postinoculation).

In phase 0 , cows were free of mammary infection (no growth in milk) and had SCC of $14.5 \times 10^{3}$ cells $/ \mathrm{mL}$ (range: $8 \times 10^{3}$ to $37 \times 10^{3}$ cells $/ \mathrm{mL}$; Figure 3 ). We detected a significant increase in E. coli concentration in phase 1 (median, $5.52 \times 10^{3} \mathrm{cfu} / \mathrm{mL}$; range: $2.5 \times$ $10^{2}$ to $4.40 \times 10^{5} \mathrm{cfu} / \mathrm{mL}$ ), followed by a decrease in phase $2\left(5.05 \times 10^{3} \mathrm{cfu} / \mathrm{mL}\right.$; range: $4.70 \times 10^{2}$ to 2.90 $\left.\times 10^{5} \mathrm{cfu} / \mathrm{mL}\right)$ and phase $3\left(3.85 \times 10^{2} \mathrm{cfu} / \mathrm{mL}\right.$; range: $0-1.56 \times 10^{5} \mathrm{cfu} / \mathrm{mL}$; Figure 3$)$. A significant increase in SCC was observed in phase 2 (median, $4.21 \times 10^{7}$ cells $/ \mathrm{mL}$, range: $7.27 \times 10^{6}$ to $1.96 \times 10^{8}$ cells $/ \mathrm{mL}$ ) and phase 3 (median, $1.29 \times 10^{7}$ cells $/ \mathrm{mL}$, range: $3.22 \times$ $10^{6}$ to $8.50 \times 10^{7}$ cells $/ \mathrm{mL}$ ), but values remained low in phase $1\left(6.20 \times 10^{4}\right.$ cells $/ \mathrm{mL}$, range: $9.00 \times 10^{3}$ to 1.17 $\times 10^{6}$ cells $\left./ \mathrm{mL}\right)$, compared with baseline levels $(1.45 \times$ 
$10^{4}$ cells $/ \mathrm{mL}$ range: $8.00 \times 10^{3}$ to $3.70 \times 10^{4}$ cells $/ \mathrm{mL}$; Figure 3).

\section{Cows' Lying Behavior Before Inoculation}

The percentage of undisturbed time spent lying and the number of postural changes per $24 \mathrm{~h}$ from $6 \mathrm{Hol}-$ stein-Friesian cows before inoculation with $E$. coli, from (relative to time zero, inoculation) $-23 \mathrm{~h}$ to $-17 \mathrm{~h}$ (i.e., 0000 to $0700 \mathrm{~h}$, same time of day compared with phase 1), from $-13.5 \mathrm{~h}$ to $-0.5 \mathrm{~h}$ (i.e., 1030 to $2330 \mathrm{~h}$, same time of day compared with phase 2 ), and from $-23.5 \mathrm{~h}$ to $-0.5 \mathrm{~h}$ (i.e., $2330 \mathrm{~h}$ the day before to 0030 , same

cow 1

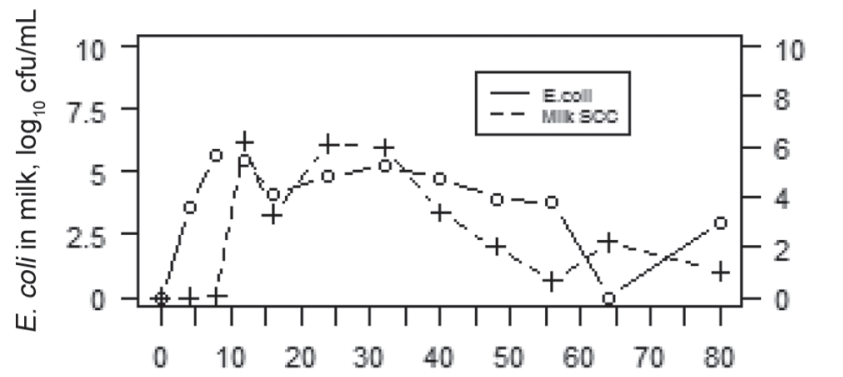

cow 3

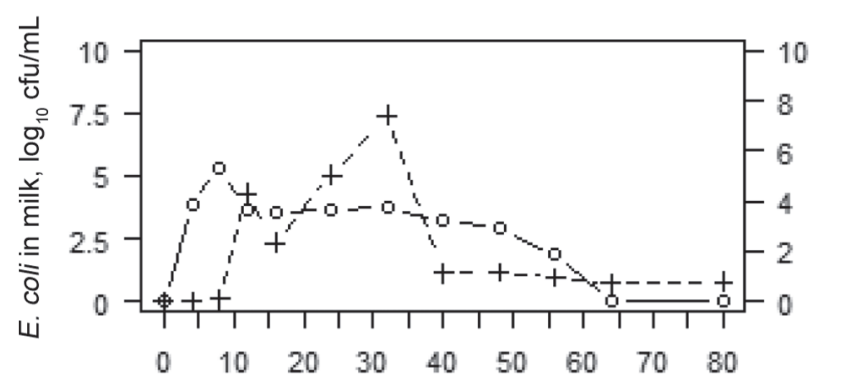

cow 5

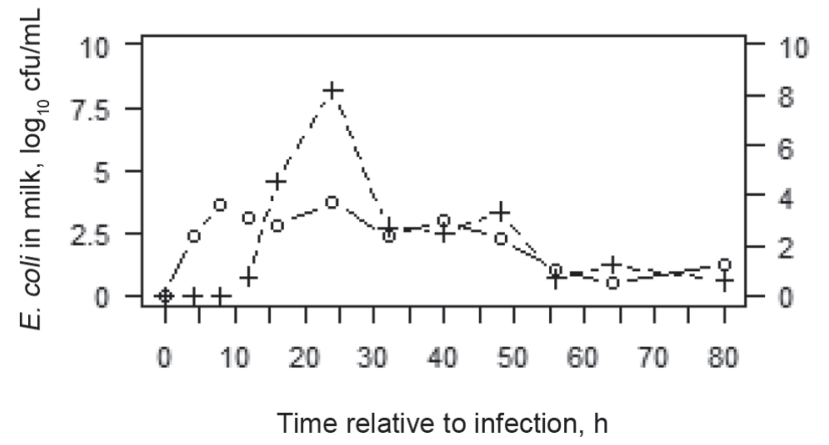

time of day compared with phase 3), are presented in Figure 4. These data were used as baseline levels to further calculate the variation in time lying and in the number of postural changes for phase 1 , phase 2 and phase 3 .

\section{Discrimination of Pain Experienced by Cows During Phases of Mastitis}

Data on all indicators are detailed in Table 2. In phase 0 , cows had low levels for all variables. Compared with phase 0 , cows in phase 1 changed position (lying/standing) less often $(P<0.05)$, were less attentive

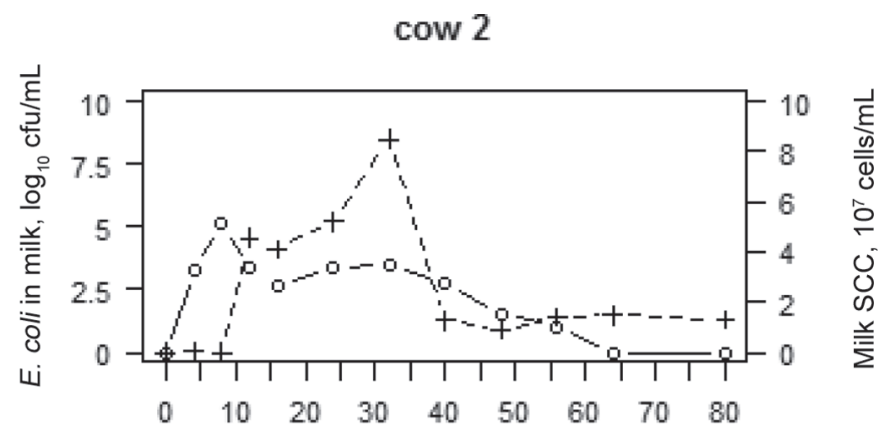

cow 4

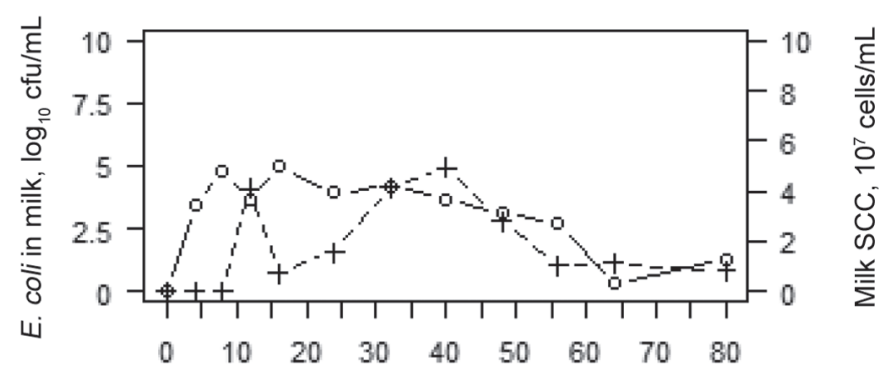

cow 6

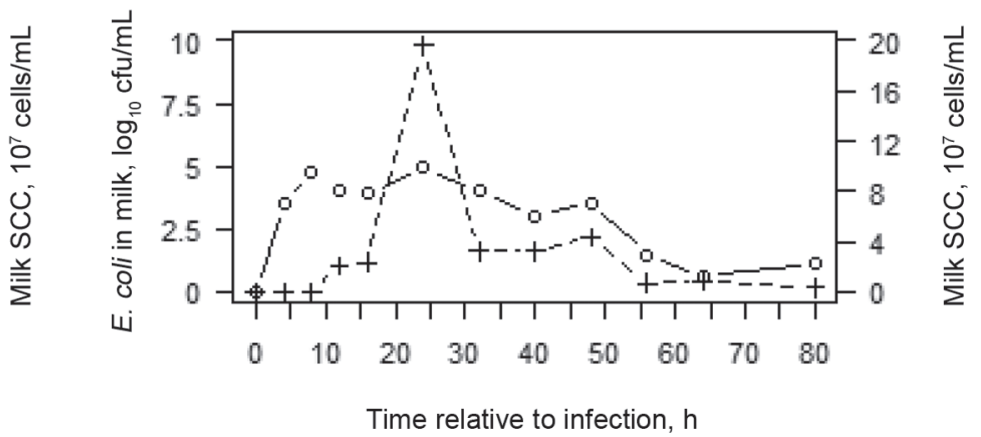

Figure 2. Individual changes in Escherichia coli count in milk $\left(\log _{10} \mathrm{cfu} / \mathrm{mL}\right)$ and SCC in milk $\left(10^{7}\right.$ cells $\left./ \mathrm{mL}\right)$ from 6 Holstein-Friesian cows inoculated with $E$. coli at 0 h. 
toward their surroundings and had lower head positions $(P<0.05)$, and showed a small (but nonsignificant) increase in cortisol level $(P=0.06)$. Compared with phase 0 , cows in phase 2 were less attentive toward their surroundings and had lower head positions $(P<0.05)$, showed more clinical signs $(P<0.05)$; they also had higher cortisol, SAA and ruminal temperature levels $(P$ $<0.05)$. Finally, cows in phase 3 had higher haptoglobin and SAA levels and higher GSH/GSSG ratio than in phase $0(P<0.05)$ but showed no changes in their behavior, in cortisol level, or ruminal temperature.

Discrimination of the 4 phases was tested (Table 3 and Figure 5). Axes 1 and 2 contributed to 61.9 and

\section{E. coli in milk}

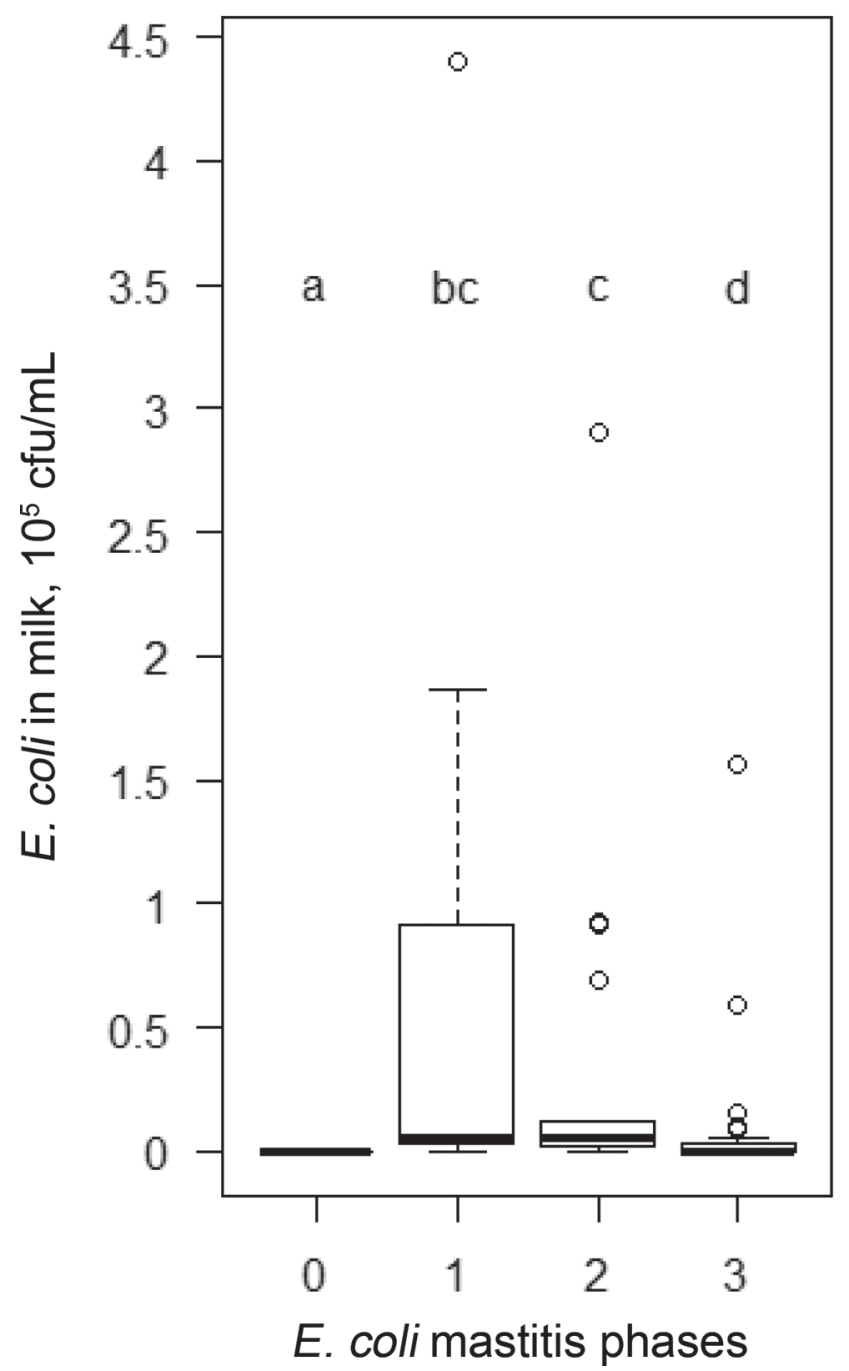

$37.2 \%$, respectively, of the variance explained by the model. Axis 1 was mostly explained (correlation of each variable to the component) by ruminal temperature (-85.8), cortisol (-76.2), haptoglobin (67.7), cows' tail position (-51.4), SAA (41.8), cows' attention and head position $(-30)$, and variation in the number of postural changes per hour (30.9). This axis opposed cows in phase 2 to cows in phase 3 , with cows in phases 0 and 1 being intermediate.

Axis 2 was mostly explained by SAA (87.1), cows' clinical signs (72.1), haptoglobin (71.6), cortisol (46.7), cows' tail position (44.7), ruminal temperature (43.5), and ear position (30.5). This axis opposed cows in

Figure 3. Changes in Escherichia coli count in milk $\left(10^{5} \mathrm{cfu} / \mathrm{mL}\right)$ and $\mathrm{SCC}$ in milk $\left(10^{7}\right.$ cells $\left./ \mathrm{mL}\right)$ from 6 Holstein-Friesian cows inoculated with E. coli, at $0 \mathrm{~h}$ in phase 0 (before inoculation), phase 1 ( 4 to $8 \mathrm{~h}$ postinoculation), phase 2 (12 to $24 \mathrm{~h}$ postinoculation), and phase 3 ( 32 to $80 \mathrm{~h}$ postinoculation). Plots with different letters (a-d) differ significantly at $P<0.05$. Line represents the median $(50 \%$ of data is greater than this value, which is the middle of data set); box represents the upper ( $25 \%$ of data are greater than this value) and lower ( $25 \%$ of data less than this value) quartiles; whiskers represent the minimum (least value, excluding outliers) and the maximum (i.e., greatest value, excluding outliers); and open circles represent outliers (more than 3/2 times of upper quartile or less than $3 / 2$ times of lower quartile). 
phases 0 and 1 to cows in phases 2 and 3. Figure 4 suggests that (1) the lower the level of the indicators, the more likely the cow is to be in phase $0 ;(2)$ the higher the ruminal temperature, cortisol level, and scores for attention and head position, tail position, and the lower the variation of number of postural changes, the more likely the cow is to be in phase 2, and (3) the higher the haptoglobin and SAA levels and score for clinical signs, the more likely the cow is to be in phase 3 . After cross-validation, the cows were correctly classified in their original phases for phases 2 and 3 , but with lower performance for phases 0 and 1 (Table 4 ).

\section{DISCUSSION}

More attention has been focused on pain associated with mastitis over the last decade, but generally only 1 or 2 types of indicators are explored at a time (e.g., behavior, clinical signs, or inflammation). To our knowledge, this study is the first to give a more extensive overview of the whole response, including possible signs of pain, to a mammary challenge, integrating all aspects (behavior, stress response, inflammation, and oxidative stress). This study is also one of the first to define the timeline of behavioral and physiological observation according to $E$. coli growth in the udder and the cow's immune response (SCC). Previous studies described such responses, but summarized and presented the data for each day (e.g., at $\mathrm{d}+1,+2,+3$, and so on; Fogsgaard et al., 2012). Here, we defined the timeline of observation according to the phases of the disease (preclinical, acute, and remission), and identified the most painful phases. Despite a small number of dairy cows, the findings raise new hypotheses to be tested in larger controlled studies in the field. Our findings should be evaluated against a distinct, separate, and larger set of observations to further validate the model proposed here. These data could be provided by different mastitis challenge experiments (e.g., Staphylococcus aureus, Streptococcus uberis, or other E. coli stains) or from naturally occurring clinical cases of mastitis in which the pathogen would have been identified. In addition, the timeline of the cows' response to other pathogens and the associated signs of sickness and of pain should be monitored: some data are available for several E. coli strains, but less regarding Strep. uberis (Kester et al., 2015) or Staph. aureus. Such knowledge will allow farmers and veterinarians to identify when a cow is experiencing pain and to initiate pain relief treatment accordingly.

The short- and medium-term effects of E. coli udder inoculation were assessed using both immediate and less immediate indicators. Variations in plasma cortisol and behavior are widely used as indicators of stress in studies on painful procedures such as dehorning or castration (Grøndahl-Nielsen et al., 1999; Coetzee, 2013; Millman, 2013), and also during mastitis (Hopster et al., 1998; Leslie and Petersson-Wolfe, 2012). In these studies, cortisol concentrations increased 2- to 5-fold compared with controls, reflecting high stress levels induced by pain. In our study, we used these indicators alongside less immediate indicators of inflammation (Eckersall et al., 2001) and oxidative stress (Salvemini et al., 2011; Sharma et al., 2016) to obtain a comprehensive overview of the pain experienced by cows.

Before inoculation, baseline levels of plasma cortisol, haptoglobin, SAA, and ruminal body temperature corresponded to the basal values reported in the literature
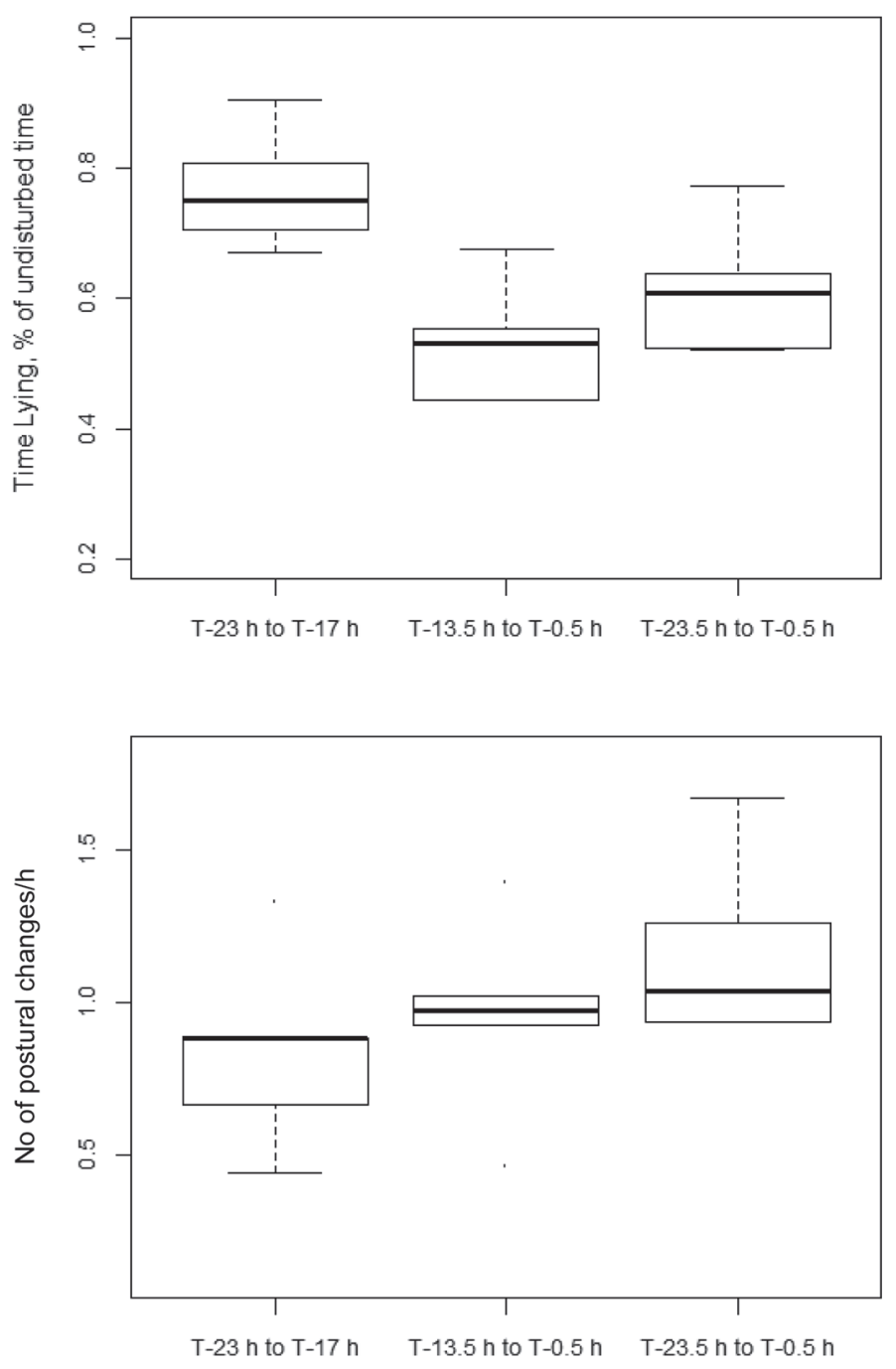

Figure 4. Percentage of undisturbed time spent lying (top panel) and number of postural changes per $24 \mathrm{~h}$ (bottom panel) from 6 Holstein-Friesian cows before inoculation with Escherichia coli, relative to time $(\mathrm{T}) 0$ (time of inoculation): $\mathrm{T}-23 \mathrm{~h}$ to $\mathrm{T}-17 \mathrm{~h}$ (i.e., same moment in the day as phase 1 ), from $\mathrm{T}-13.5 \mathrm{~h}$ to $\mathrm{T}-0.5 \mathrm{~h}$ (i.e., same moment in the day as phase 2 ), and from $\mathrm{T}-23.5 \mathrm{~h}$ to $\mathrm{T}-0.5 \mathrm{~h}$ (i.e., same moment in the day as phase 3). 
Table 2. Median values [minimum-maximum] of indicators from 6 Holstein-Friesian cows inoculated with Escherichia coli at 0 h before inoculation (phase 0 ), phase 1 ( 4 to $8 \mathrm{~h}$ postinoculation), phase 2 (12 to $24 \mathrm{~h}$ postinoculation), and phase 3 (32 to $80 \mathrm{~h}$ postinoculation)

\begin{tabular}{|c|c|c|c|c|}
\hline Indicator & Phase 0 & Phase 1 & Phase 2 & Phase 3 \\
\hline \multicolumn{5}{|l|}{ Behavior } \\
\hline \multicolumn{5}{|l|}{ Score, 0 to 1 value scale } \\
\hline Ear position & $0.13[0.00-0.25]$ & $0.50[0.00-1.00]$ & $0.50[0.00-1.00]$ & $0.50[0.00-1.00]$ \\
\hline Facial expression & $0.00[0.00-0.00]$ & $0.00[0.00-0.00]$ & $0.00[0.00-0.00]$ & $0.00[0.00-0.00]$ \\
\hline Standing posture & $0.00[0.00-0.00]$ & $0.00[0.00-0.00]$ & $0.00[0.00-0.00]$ & $0.00[0.00-0.00]$ \\
\hline Limb posture & $0.00[0.00-0.25]$ & $0.00[0.00-0.00]$ & $0.00[0.00-0.33]$ & $0.00[0.00-0.40]$ \\
\hline Tail position & $0.00[0.00-0.00]$ & $0.00[0.00-0.00]$ & $0.25[0.00-0.50]$ & $0.05[0.00-0.10]$ \\
\hline Clinical signs & $0.00[0.00-0.05]^{\mathrm{a}}$ & $0.00[0.00-0.00]^{\mathrm{a}}$ & $0.07[0.00-0.07]^{\mathrm{b}}$ & $0.08[0.00-0.16]^{\mathrm{ab}}$ \\
\hline Time lying, \% (variation from baseline ${ }^{1}$ ) & $1.00[1.00-1.00]$ & $1.05[0.77-1.26]$ & $0.98[0.91-1.84]$ & $1.11[0.94-1.25]$ \\
\hline No. of postural changes/h (variation from & $1.00[1.00-1.00]^{\mathrm{a}}$ & $0.75[0.33-1.00]^{\mathrm{b}}$ & $0.92[0.33-1.00]^{\mathrm{ab}}$ & $1.01[0.71-1.15]^{\mathrm{a}}$ \\
\hline & & & & \\
\hline \multicolumn{5}{|l|}{ Inflammation } \\
\hline Haptoglobin, mg/mL & $0.00[0.00-0.00]^{\mathrm{a}}$ & $0.00[0.00-0.00]^{\mathrm{a}}$ & $0.05[0.00-0.07]^{a c}$ & $0.57[0.47-0.76]^{\mathrm{bc}}$ \\
\hline GSH/GSSG ratio $^{2}$ & $0.13[0.06-0.50]^{\mathrm{ab}}$ & $0.14[0.09-0.31]^{\mathrm{a}}$ & $0.16[0.11-0.32]^{\mathrm{ab}}$ & $0.21[0.19-0.42]^{\mathrm{b}}$ \\
\hline
\end{tabular}

Table 3. Factorial discriminant analysis on physiological and behavioral indicators from 6 Holstein-Friesian cows inoculated with Escherichia coli indicating proportion of variance explained by each component and correlation of each variable to the component ${ }^{1}$

\begin{tabular}{|c|c|c|}
\hline Factorial discriminant analysis & Axis 1 & Axis 2 \\
\hline Eigenvalue & 0.98 & 0.92 \\
\hline Total variance explained by component, \% & 61.9 & 37.2 \\
\hline \multicolumn{3}{|l|}{ Contribution of each variable to components } \\
\hline Attention and head position* & -30.0 & 18.0 \\
\hline Ear position & -13.0 & 30.5 \\
\hline Limb posture & 12.6 & 24.7 \\
\hline Lying position & 2.1 & -16.7 \\
\hline Miscellaneous abnormal behaviors & -13.5 & 27.5 \\
\hline Tail position* & -51.4 & 44.7 \\
\hline Clinical signs* & 11.8 & 72.1 \\
\hline $\begin{array}{l}\text { Variation in time lying, \% (total undisturbed } \\
\text { time) }\end{array}$ & -16.6 & 26.9 \\
\hline $\begin{array}{l}\text { Variation in no. of postural changes } / \mathrm{h} \\
\text { (undisturbed time)* }\end{array}$ & 30.9 & 9.5 \\
\hline \multicolumn{3}{|l|}{ Inflammation } \\
\hline Haptoglobin, mg/mL* & 67.7 & 71.6 \\
\hline Serum amyloid A, $\mu \mathrm{g} / \mathrm{mL}^{*}$ & 41.8 & 87.1 \\
\hline Ruminal temperature, ${ }^{\circ} \mathrm{C}^{*}$ & -85.8 & 43.5 \\
\hline \multicolumn{3}{|l|}{ Hypothalamic-pituitary-adrenal axis } \\
\hline Cortisol, $\mathrm{ng} / \mathrm{mL}^{*}$ & -76.2 & 46.7 \\
\hline \multicolumn{3}{|l|}{ Oxidative stress } \\
\hline GSH/GSSG ratio $^{2}$ & 23.2 & 18.9 \\
\hline
\end{tabular}

${ }^{1}$ Bold indicates variables that contributed most to the component.

${ }^{2}$ Ratio of oxidized and reduced glutathione.

*Variable differed significantly between phases $(P<0.05)$.
(Hopster et al., 1998; Eckersall et al., 2001; Wenz et al., 2001). The cows expressed no particular behavioral signs of sickness (González et al., 2008; Fogsgaard et al., 2012) or pain (Weary et al., 2006). They spent $55.5 \%$ of their undisturbed time lying and changed position 1.18 times per hour, slightly higher than previously published studies on healthy cattle (Ito et al., 2009; Fogsgaard et al., 2012). Thus, before inoculation, the 6 cows did not appear to experience any kind of pain or discomfort.

Escherichia coli proliferated rapidly in milk within 8 $\mathrm{h}$ postinoculation, reaching concentrations above $5.5 \times$ $10^{3} \mathrm{cfu} / \mathrm{mL}$. This was followed, 12 to $24 \mathrm{~h}$ postinoculation, by a steep increase in SCC due to a huge influx of white blood cells in the milk. This resulted in a decrease in the E. coli population, which reverted to baseline levels from 32 to $80 \mathrm{~h}$ postinoculation. Although interindividual variations were observed, the profiles of the $E$. coli development and cellular response of the 6 cows fit the typical overall pattern described in the literature (Schukken et al., 2011). Because the severity of the mastitis disease correlates strongly with $E$. coli count in milk (Schukken et al., 2011), we proposed to assign the mastitis course into 4 phases as follow: baseline (phase $0)$, preclinical phase $(0-8 \mathrm{~h}$ postinoculation, phase 1$)$, acute phase (12-24 h postinoculation, phase 2$)$, and remission phase $(32-80 \mathrm{~h}$ postinoculation, phase 3 ).

For the first $8 \mathrm{~h}$ postinoculation, E. coli bacteria increased in milk. Simultaneously, SCC and inflam- 

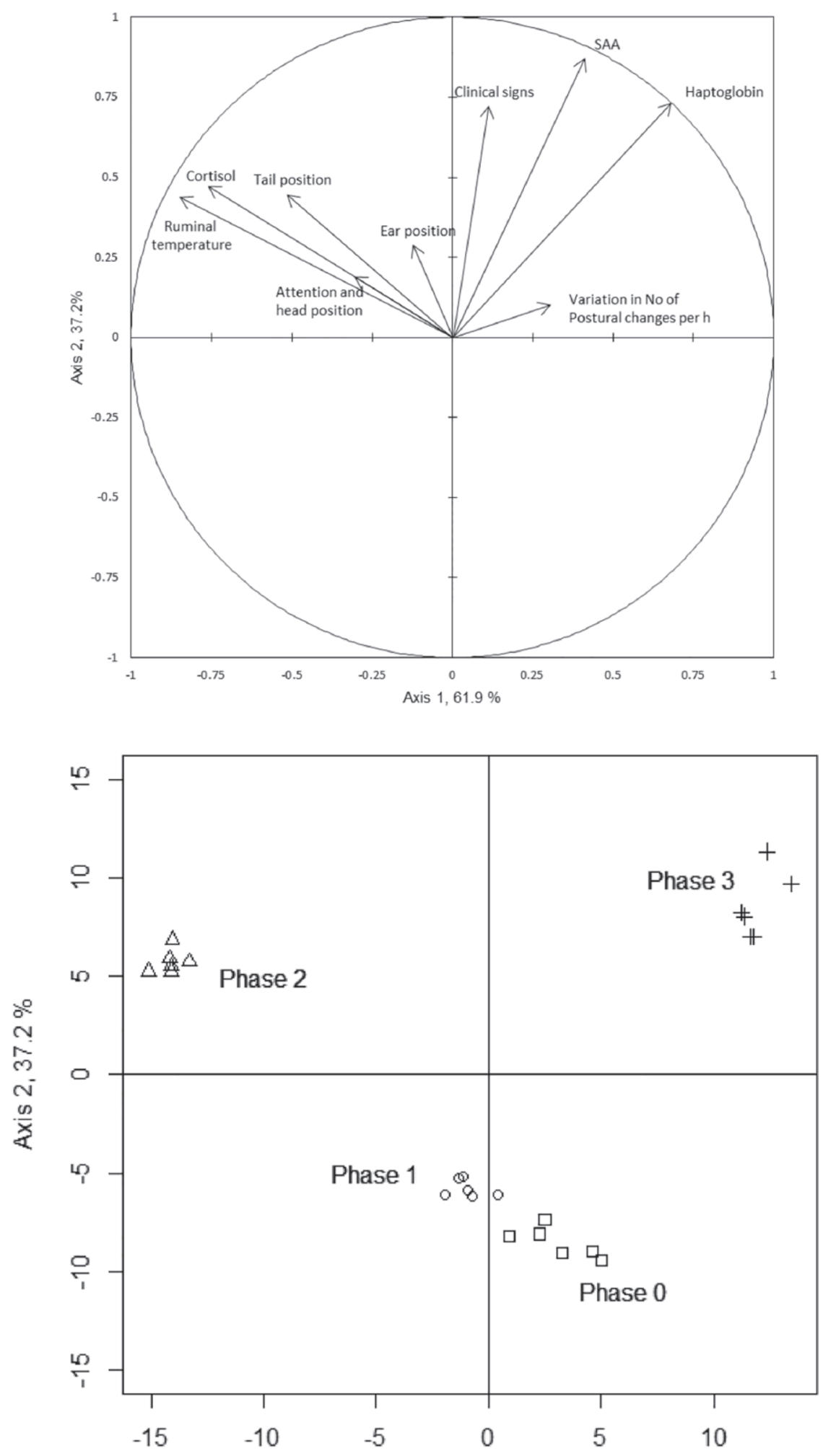

Axis $1,61.9 \%$

Figure 5. Factorial discriminant analysis on physiological and behavioral indicators from 6 Holstein-Friesian cows inoculated with Escherichia coli, in phase 0 (before inoculation), phase 1 ( 4 to $8 \mathrm{~h}$ postinoculation), phase 2 (12 to $24 \mathrm{~h}$ postinoculation), and phase 3 (32 to $80 \mathrm{~h}$ postinoculation): loadings of the variables with an absolute correlation $>0.30$ (A) and of the individuals (B) on axis 1 and axis 2 of the factorial discriminant analysis. SAA = serum amyloid A. 
mation markers (haptoglobin, SAA, and ruminal body temperature) remained at baseline levels, and a very small increase in plasma cortisol level $(P=0.06)$ was observed, illustrating the beginning of the stress response. Cows expressed behavioral changes: they were less attentive toward their surroundings and changed less often their posture (lying/standing), which could be due to the endotoxin response. Siivonen et al. (2011) also reported longer standing bouts on the day following an LPS challenge, whereas Cyples et al. (2012) did not find variation in the duration of lying bouts following LPS challenge. An LPS challenge nevertheless does not reflect on-farm conditions because, unlike our experimental procedure, LPS-associated mastitis does not involve live bacteria. Rather, our findings reflect the typical decrease in activity observed in sick animals (Veissier et al., 2017) as described following an E. coli challenge (Fogsgaard et al., 2012). Cows may also have moved less to limit the pressure on the udder when changing posture (e.g., from standing to lying; Stewart et al., 2017). In addition, cows were less attentive toward their surroundings and lowered their heads. This behavior has been described in cattle experiencing sickness (Hart, 1988) and also in several painful situations (for a review, see Weary et al., 2006). Our findings are consistent with those of Gleerup et al. (2015), who included 2 mastitic cows in their sample. Hence, during the initial phase of $E$. coli proliferation, dairy cows may experience some discomfort due to sickness. Pain is a stressor that causes a biological stress response ( Viñuela-Fernández et al., 2011). Here, behavioral changes were not associated with a stress response, suggesting that cows did not feel pain during the preclinical phase of mastitis. Observed sickness-related changes could be due to systemic effects of bacteria development rather than local pain due to inflammation.

During the mastitis acute phase, E. coli concentrations started to decrease, and SCC increased, enabling inhibition of bacterial growth through phagocytosis and killing (Schukken et al., 2011). Cows had high levels of SAA and increased ruminal temperature, parameters associated with an inflammatory response (Eckersall et al., 2001; Schukken et al., 2011). The timeline of these responses was similar to that in previous studies
(Fitzpatrick et al., 2013). In these animals, Herry et al. (2017) reported a peak in concentration of the 3 major proinflammatory cytokines - tumor necrosis factor- $\alpha$, IL-1 $\beta$, and IL-6 - at $12 \mathrm{~h}$ postinoculation. Cows kept displaying behavioral changes related to sickness (they were less attentive toward their surroundings) and they had higher cortisol levels. Cortisol elevation has been investigated poorly during mastitis although it is a good indicator of the stress response (Hopster et al., 1998). The magnitude of the cortisol response observed here $(35 \mathrm{ng} / \mathrm{mL}$ ) in response to E. coli mastitis was higher than values previously reported in studies on mastitis following $E$. coli LPS challenge $(25 \mathrm{ng} / \mathrm{mL}$; Hopster et al., 1998), during ruminocentesis without anesthesia (14.5 ng/mL; Mialon et al., 2012), or disbudding of calves without anesthesia $(4.5 \mathrm{ng} / \mathrm{mL}$; Caray et al., 2015). Our results suggest that cows probably experienced high levels of stress at the start of the inflammatory response and displayed behavioral changes. Additional measures of nociception (Fitzpatrick et al., 2013) would have helped us to better understand whether the observed changes were due to sickness behavior or pain per se. However, according to the behavioral and physiological responses observed, we assume that the acute phase of mastitis might have been associated with cows feeling pain.

The remission phase was characterized by an E. coli count close to baseline level and high SCC, albeit lower than in phase 2. Simultaneously, cows had high levels of haptoglobin and SAA. They did not display behavioral or stress responses: these indicators (behavior and cortisol) had returned to their baseline levels. It seems therefore that although the cows were still in an inflammatory stage (Eckersall et al., 2001; Schukken et al., 2011), the remission phase of mastitis was not associated with cows experiencing discomfort, sickness, or pain.

The animals were fitted with data loggers and rumen temperature sensors - devices used in precision livestock farming. We found that a decrease in the number of postural changes was associated with E. coli population growth, and that an increase in ruminal temperature was associated with the start of immune response. Our results suggest that automated lying

Table 4. Cross validation of the factorial discriminant analysis (accuracy, sensitivity and specificity) on physiological and behavioral indicators from 6 Holstein-Friesian cows inoculated with Escherichia coli in phase 0 (before inoculation), phase 1 ( 4 to 8 h postinoculation), phase 2 (12 to $24 \mathrm{~h}$ postinoculation), and phase 3 (32 to $80 \mathrm{~h}$ postinoculation)

\begin{tabular}{|c|c|c|c|c|c|c|c|}
\hline From/toward ${ }^{1}$ & Phase 0 & Phase 1 & Phase 2 & Phase 3 & Accuracy, \% & Sensitivity, \% & Specificity, \% \\
\hline Phase 1 & 2 & 4 & 0 & 0 & 83.3 & 66.7 & 88.9 \\
\hline Phase 2 & 0 & 0 & 6 & 0 & 100 & 100 & 100 \\
\hline
\end{tabular}

${ }^{1}$ After cross-validation, the 6 cows in phase 0 were classified as follows: 4 cows in phase 0 and 2 cows in phase 1. 
behavior and ruminal temperature recordings could be valuable on-farm tools for early detection of mastitis, especially to detect the phase of the disease and the associated pain and discomfort in cattle. However, because all animals involved in the current study were healthy before inoculation and the E. coli mastitis was experimentally induced, the knowledge gathered here from the preclinical phase (phase 1) cannot be directly applied to cows in commercial settings, especially for early detection of E. coli mastitis. Although we took the circadian rhythm of the animal into account in the analysis, our results must be carefully interpreted, especially because lying behavior was recorded during small bouts. Additional studies with a larger number of undisturbed cows are needed to further validate these hypotheses and to propose models of early detection of disease in dairy cows.

\section{CONCLUSIONS}

The present study showed changes in behavior, inflammation, and stress levels in dairy cows after udder inoculation with $E$. coli, indicating that the cows may have felt pain during this period. From E. coli and SCC counts in milk, we characterized 4 phases of the disease: before inoculation, preclinical, acute, and remission. The multiparametric approach showed good performance in discriminating these phases. Behavior, inflammation, and the HPA axis played the most important part in this discrimination, confirming that a combination of indicators increases the chance of detecting pain and assessing its intensity. Behavior and HPA axis, but not inflammation indicators, were found to be useful in early detection of mastitis. Cows seemed to experience discomfort during the preclinical phase and pain during the acute phase of the disease. The remission phase did not seem to induce any discomfort in the animals. Pain always has negative effects on animal welfare. Accordingly, when preclinical and acute phases of mastitis are detected in dairy cows, pain relief treatment should be considered. However, additional specific measures of pain response assessed (e.g., pain threshold response; weight shifting between the rear legs; or by flinch, step, and kick response during milking) could help to characterize the level of pain experienced by the cow according to the phase of the disease and thus to alleviate it. This would improve animal welfare and potentially reach the remission phase faster.

\section{ACKNOWLEDGMENTS}

This work was supported by the project KOlimastIR of the Animal Health and Welfare (ANIHWA) Era-Net (www.anihwa.eu). The authors are grateful for the efforts of the animal caretakers from the Plate-forme d'Infectiologie Expérimentale (PFIE) Institut National de la Recherche Agronomique (INRA), Nouzilly, France, for excellent animal husbandry.

\section{REFERENCES}

Arlot, S., and A. Celisse. 2010. A survey of cross-validation procedures for model selection. Statist. Surv. 4: 40-79. https://doi.org/ 10.1214/09-SS054.

Auboiron, S., D. A. Sparrow, L. Beaubatie, D. Bauchart, J. T. Sparrow, P. M. Laplaud, and M. J. Chapman. 1990. Characterization and amino-terminal sequence of apolipoprotein AI from plasma high density lipoproteins in the preruminant calf, Bos spp. Biochem. Biophys. Res. Commun. 166:833-839.

Bareille, N., L. Videcoq, J.-B. Davière, M. Johan, S. Godin, E. LeyratBousquet, J.-P. Lemonnier, J.-M. Lamy, and A. Chanvallon. 2014. Detection of the health disorders of dairy cows by the measurement of their ruminal temperature. Pages 15-18 in Rencontres Recherches Ruminants. 21st ed. INRA, Paris, France.

Blum, S., N. Sela, E. D. Heller, S. Sela, and G. Leitner. 2012. Genome analysis of bovine-mastitis-associated Escherichia coli O32: H37 strain P4. J. Bacteriol. 194:3732. https://doi.org/10.1128/JB $.00535-12$.

Boissy, A., and M. F. Bouissou. 1994. Effects of androgen treatment on behavioral and physiological responses of heifers to fear-eliciting situations. Horm. Behav. 28:66-83. https://doi.org/10.1006/hbeh .1994.1006.

Caray, D., A. de Boyer des Roches, S. Frouja, S. Andanson, and I. Veissier. 2015. Hot-iron disbudding: stress responses and behavior of 1 - and 4-week-old calves receiving anti-inflammatory analgesia without or with sedation using xylazine. Livest. Sci. 179:22-28. https://doi.org/10.1016/j.livsci.2015.05.013.

Coetzee, J. F. 2013. Assessment and management of pain associated with castration in cattle. Vet. Clin. North Am. Food Anim. Pract. 29:75-101. https://doi.org/10.1016/j.cvfa.2012.11.002.

Cyples, J. A., C. E. Fitzpatrick, K. E. Leslie, T. J. DeVries, D. B. Haley, and N. Chapinal. 2012. Short communication: The effects of experimentally induced Escherichia coli clinical mastitis on lying behavior of dairy cows. J. Dairy Sci. 95:2571-2575. https://doi .org/10.3168/jds.2011-5135.

de Oliveira, F. A., S. P. L. Luna, J. B. do Amaral, K. A. Rodrigues, A. C. Sant'Anna, M. Daolio, and J. T. Brondani. 2014. Validation of the UNESP-Botucatu unidimensional composite pain scale for assessing postoperative pain in cattle. BMC Vet. Res. 10:200. https://doi.org/10.1186/s12917-014-0200-0.

Eckersall, P. D., F. J. Young, C. McComb, C. J. Hogarth, S. Safi, A. Weber, T. McDonald, A. M. Nolan, and J. L. Fitzpatrick. 2001. Acute phase proteins in serum and milk from dairy cows with clinical mastitis. Vet. Rec. 148:35-41.

European Food Safety Authority. 2009. Scientific report of EFSA prepared by the Animal Health and Animal Welfare Unit (AHAW) on the effect of farming systems on dairy cow welfare and disease. Annex to the EFSA Journal 1143:284. http://www.efsa.europa.eu/ en/efsajournal/doc/1143r.pdf.

Faure, M., V. Paulmier, A. Boissy, A. de la Foye, A. de Boyer des Roches, and D. Durand. 2017. A multiparametric approach to discriminate the impacts of different levels of invasiveness of surgical procedures in sheep. Animal https://doi.org/10.1017/ S1751731117000805.

Fitzpatrick, C. E., N. Chapinal, C. S. Petersson-Wolfe, T. J. DeVries, D. F. Kelton, T. F. Duffield, and K. E. Leslie. 2013. The effect of meloxicam on pain sensitivity, rumination time, and clinical signs in dairy cows with endotoxin-induced clinical mastitis. J. Dairy Sci. 96:2847-2856. https://doi.org/10.3168/jds.2012-5855.

Fitzpatrick, J. L., A. M. Nolan, F. J. Young, C. J. Hogarth, T. Mc Donald, A. Weber, P. D. Eckersall, and H. C. Davidsmon. 2000. Objective measurement of pain and inflammation in dairy cows with clinical mastitis. Page 416 in Proc. Int. Symp. Veterinary Epidemiology and Economics, Breckenridge, CO. International 
Symposia on Veterinary Epidemiology and Economics, Breckenridge, $\mathrm{CO}$.

Flecknell, P. 2008. Analgesia from a veterinary perspective. Br. J. Anaesth. 101:121-124. https://doi.org/10.1093/bja/aen087.

Fogsgaard, K. K., T. W. Bennedsgaard, and M. S. Herskin. 2015. Behavioral changes in freestall-housed dairy cows with naturally occurring clinical mastitis. J. Dairy Sci. 98:1730-1738. https://doi .org $/ 10.3168 /$ jds.2014-8347.

Fogsgaard, K. K., C. M. Røntved, P. Sørensen, and M. S. Herskin. 2012. Sickness behavior in dairy cows during Escherichia coli mastitis. J. Dairy Sci. 95:630-638. https://doi.org/10.3168/jds.2011 $-4350$

Gleerup, K. B., P. H. Andersen, L. Munksgaard, and B. Forkman. 2015. Pain evaluation in dairy cattle. Appl. Anim. Behav. Sci. 171:25-32. https://doi.org/10.1016/j.applanim.2015.08.023.

González, L. A., B. J. Tolkamp, M. P. Coffey, A. Ferret, and I. Kyriazakis. 2008. Changes in feeding behavior as possible indicators for the automatic monitoring of health disorders in dairy cows. J. Dairy Sci. 91:1017-1028. https://doi.org/10.3168/jds.2007-0530.

Grøndahl-Nielsen, C., H. B. Simonsen, J. Damkjer Lund, and M. Hesselholt. 1999. Behavioural, endocrine and cardiac responses in young calves undergoing dehorning without and with use of sedation and analgesia. Vet. J. 158:14-20. https://doi.org/10.1053/tvjl .1998 .0284 .

Hart, B. L. 1988. Biological basis of the behavior of sick animals. Neurosci. Biobehav. Rev. 12:123-137. https://doi.org/10.1016/S0149 -7634(88)80004-6.

Herry, V., C. Gitton, G. Tabouret, M. Repérant, L. Forge, C. Tasca, F. B. Gilbert, E. Guitton, C. Barc, C. Staub, D. G. E. Smith, P. Germon, G. Foucras, and P. Rainard. 2017. Local immunization impacts the response of dairy cows to Escherichia coli mastitis. Sci. Rep. 7:3441. https://doi.org/10.1038/s41598-017-03724-7.

Hopster, H., J. T. N. van der Werf, and H. J. Blokhuis. 1998. Stress enhanced reduction in peripheral blood lymphocyte numbers in dairy cows during endotoxin-induced mastitis. Vet. Immunol. Immunopathol. 66:83-97. https://doi.org/10.1016/S0165-2427(98)00189-5.

Hudson, C., H. Whay, and J. Huxley. 2008. Recognition and management of pain in cattle. In Pract. 30:126-134. https://doi.org/10 .1136 inpract.30.3.126.

Huxley, J. N., and H. R. Whay. 2006. Current attitudes of cattle practitioners to pain and the use of analgesics in cattle. Vet. Rec. 159:662-668. https://doi.org/10.1136/vr.159.20.662.

Ito, K., D. M. Weary, and M. A. G. Von Keyserlingk. 2009. Lying behavior: Assessing within- and between-herd variation in freestallhoused dairy cows. J. Dairy Sci. 92:4412-4420. https://doi.org/10 .3168/jds.2009-2235.

Kester, H. J., D. E. Sorter, and J. S. Hogan. 2015. Activity and milk compositional changes following experimentally induced Streptococcus uberis bovine mastitis. J. Dairy Sci. 98:999-1004. https:// doi.org/10.3168/jds.2014-8576.

Lebart, L., M. Piron, and A. Morineau. 1995. Statistique exploratoire multidimensionnelle. Dunod, Paris, France. http:// horizon.documentation.ird.fr/exl-doc/pleins_textes/divers11-10/ 010007837.pdf.

Leslie, K. E., and C. S. Petersson-Wolfe. 2012. Assessment and management of pain in dairy cows with clinical mastitis. Vet. Clin. North Am. Food Anim. Pract. 28:289-305. https://doi.org/10 $.1016 /$ j.cvfa.2012.04.002.

Martin, J., and I. N. H. White. 1991. Fluorimetric determination of oxidised and reduced glutathione in cells and tissues by highperformance liquid chromatography following derivatization with dansyl chloride. J. Chromatogr. 568:219-225. https://doi.org/10 .1016/0378-4347(91)80356-H.

Martin, P., and P. Bateson. 2013. Measuring Behaviour: An Introductory Guide. 3rd ed. Cambridge University Press, Cambridge, UK.

McDougall, S., M. A. Bryan, and R. M. Tiddy. 2009. Effect of treatment with the nonsteroidal antiinflammatory meloxicam on milk production, somatic cell count, probability of re-treatment, and culling of dairy cows with mild clinical mastitis. J. Dairy Sci. 92:4421-4431. https://doi.org/10.3168/jds.2009-2284.

Mialon, M.-M., V. Deiss, S. Andanson, F. Anglard, M. Doreau, and I. Veissier. 2012. An assessment of the impact of rumenocentesis on pain and stress in cattle and the effect of local anaesthesia. Vet. J. 194:55-59. https://doi.org/10.1016/j.tvjl.2012.02.019.

Millman, S. T. 2013. Behavioral responses of cattle to pain and implications for diagnosis, management, and animal welfare. Vet. Clin. North Am. Food Anim. Pract. 29:47-58. https://doi.org/10.1016/ j.cvfa.2012.11.007.

Mølgaard, L., B. M. Damgaard, V. Bjerre-Harpøth, and M. S. Herskin. 2012. Effects of percutaneous needle liver biopsy on dairy cow behaviour. Res. Vet. Sci. 93:1248-1254. https://doi.org/10.1016/ j.rvsc.2012.04.001.

Molony, V., and J. E. Kent. 1997. Assessment of acute pain in farm animals using behavioral and physiological measurements. J. Anim. Sci. $75: 266-272$

Prunier, A., L. Mounier, P. Le Neindre, C. Leterrier, P. Mormede, V. Paulmier, P. Prunet, C. Terlouw, and R. Guatteo. 2013. Identifying and monitoring pain in farm animals: A review. Animal 7:998-1010. https://doi.org/10.1017/S1751731112002406.

R Core Team. 2014. R Version 2.14.03.3.2. R: A language and environment for statistical computing. R Foundation for Statistical Computing. Vienna, Austria. http://www.R-project.org/.

Robertson, I. S., J. E. Kent, and V. Molony. 1994. Effect of different methods of castration on behaviour and plasma cortisol in calves of three ages. Res. Vet. Sci. 56:8-17. https://doi.org/10.1016/0034 $-5288(94) 90189-9$

Salvemini, D., J. W. Little, T. Doyle, and W. L. Neumann. 2011. Roles of reactive oxygen and nitrogen species in pain. Free Radic. Biol. Med. 51:951-966. https://doi.org/10.1016/j.freeradbiomed .2011.01.026.

Schukken, Y. H., J. Gunther, J. Fitzpatrick, M. C. Fontaine, L. Goetze, O. Holst, J. Leigh, W. Petzl, H. J. Schuberth, A. Sipka, D. G. Smith, R. Quesnell, J. Watts, R. Yancey, H. Zerbe, A. Gurjar, R. N. Zadoks, and H. M. Seyfert. 2011. Host-response patterns of intramammary infections in dairy cows. Vet. Immunol. Immunopathol. 144:270-289. https://doi.org/10.1016/j.vetimm.2011.08 .022 .

Sharma, L., A. K. Verma, A. Rahal, A. Kumar, and R. Nigam. 2016. Relationship between serum biomarkers and oxidative stress in dairy cattle and buffaloes with clinical and sub-clinical mastitis. Biotechnology 15:96-100. https://doi.org/10.3923/biotech.2016.96 100 .

Siivonen, J., S. Taponen, M. Hovinen, M. Pastell, B. J. Lensink, S. Pyörälä, and L. Hänninen. 2011. Impact of acute clinical mastitis on cow behaviour. Appl. Anim. Behav. Sci. 132:101-106. https:// doi.org/10.1016/j.applanim.2011.04.005.

Stewart, M., M. T. Wilson, A. L. Schaefer, F. Huddart, and M. A. Sutherland. 2017. The use of infrared thermography and accelerometers for remote monitoring of dairy cow health and welfare. J. Dairy Sci. 100:3893-3901. https://doi.org/10.3168/jds.2016-12055.

Theurer, M. E., B. J. White, J. F. Coetzee, L. N. Edwards, R. A. Mosher, and C. A. Cull. 2012. Assessment of behavioral changes associated with oral meloxicam administration at time of dehorning in calves using a remote triangulation device and accelerometers. BMC Vet. Res. 8:48. https://doi.org/10.1186/1746-6148-8-48.

Veissier, I., P. Le Neindre, and G. Trillat. 1989. The use of circadian behaviour to measure adaptation of calves to changes in their environment. Appl. Anim. Behav. Sci. 22:1-12. https://doi.org/10 .1016/0168-1591(89)90075-0.

Veissier, I., M. M. Mialon, and K. H. Sloth. 2017. Early modification of the circadian organization of cows' activity in relation to disease or estrus. J. Dairy Sci. 100:3969-3974. http://dx.doi.org/https:// doi.org/10.3168/jds.2016-11853.

Viñuela-Fernández, I., D. Weary, and P. Flecknell. 2011. Pain. Pages 64-77 in Anim. Welfare. M. C. Appleby, J. A. Mench, A. S. Olsson, and B. O. Hughes, ed. CAB International, Wallingford, UK.

Weary, D. M., L. Niel, F. C. Flower, and D. Fraser. 2006. Identifying and preventing pain in animals. Appl. Anim. Behav. Sci. 100:6476. https://doi.org/10.1016/j.applanim.2006.04.013.

Wenz, J. R., G. M. Barrington, F. B. Garry, R. P. Dinsmore, and R. J. Callan. 2001. Use of systemic disease signs to assess disease severity in dairy cows with acute coliform mastitis. J. Am. Vet. Med. Assoc. 218:567-572. 